CYSTIC FIBROSIS

\title{
Multiple breath inert gas washout as a measure of ventilation distribution in children with cystic fibrosis
}

\author{
P Aurora, P Gustafsson, A Bush, A Lindblad, C Oliver, C E Wallis, J Stocks
}

Thorax 2004:59:1068-1073. doi: 10.1136/thx.2004.022590

Background: Multiple breath inert gas washout (MBW) has been suggested as a tool for detecting early cystic fibrosis (CF) lung disease. A study was undertaken to compare the relative sensitivity of $M B W$ and spirometry for detecting abnormal lung function in school age children with CF and to compare MBW results obtained from healthy children in the UK with those recently reported from Sweden.

See end of article for authors' affiliations

Methods: Forced expiratory volume in 1 second $\left(\mathrm{FEV}_{1}\right)$ and maximal expiratory flow when $25 \%$ of forced vital capacity remains to be expired $\left(\mathrm{MEF}_{25}\right)$ were compared with the lung clearance index (LCI) derived from sulphur hexafluoride MBW in 22 children with CF aged 6-16 years and in 33 healthy controls.

....................

Correspondence to: Dr P Aurora, Portex Anaesthesia, Intensive Therapy and Respiratory Medicine Unit, Institute of Child Health, 30 Guilford Street, London WCIN 1EH, UK; p.aurora@ich. ucl.ac.uk

Results: $\mathrm{LCl}$ was higher in children with $\mathrm{CF}$ than in healthy controls (mean difference $5.1195 \% \mathrm{Cl}$ of difference 4.1 to 6.1 ) and $\mathrm{FEV}_{1}$ and $\mathrm{MEF}_{25} \mathrm{z}$-scores were lower (mean difference $-2.3(95 \% \mathrm{Cl}-2.9$ to $-1.7)$ and $-1.8(95 \% \mathrm{Cl}-2.4$ to -1.3$)$, respectively; $\mathrm{p}<0.001$ for all). There was a significant negative correlation between $\mathrm{LCl}$ and $\mathrm{FEV}_{1}\left(r^{2}=0.62\right)$ and $\mathrm{MEF}_{25}\left(r^{2}=0.46\right)$. However, while normal $(\geqslant-1.96$ $z$-scores) $\mathrm{FEV}_{1}$ and $\mathrm{MEF}_{25}$ results were seen in $11(50 \%)$ and $12(53 \%)$ children with $\mathrm{CF}$, respectively, all but one of these children had an abnormally increased $\mathrm{LCl}$. $\mathrm{LCl}$ was repeatable in both groups (within subject CV for three measurements $6 \%$ for CF and $5 \%$ for healthy children). In healthy subjects $\mathrm{LCl}$ was independent of age and virtually identical in the British and Swedish children (mean difference $0.1195 \% \mathrm{Cl}$ -0.1 to 0.4$), p=0.38$ )

Received 4 February 2004 Accepted 24 June 2004

Conclusions: MBW is reproducible between laboratories, generates normal ranges which are constant over childhood, and is more frequently abnormal than spirometry in children with CF.

$\mathrm{R}$ egular lung function testing is an essential part of clinical care for children with cystic fibrosis (CF). In particular, the forced expiratory volume in 1 second $\left(\mathrm{FEV}_{1}\right)$ is commonly used to monitor disease progression in individuals, to predict prognosis in subjects with advanced lung disease, ${ }^{12}$ and as an outcome measure in clinical trials. ${ }^{3}$ Over the last two decades there has been a shift towards closer monitoring and more aggressive treatment of early CF lung disease $\mathrm{e}^{4-6}$ and, as a consequence, two major disadvantages to the use of $\mathrm{FEV}_{1}$ in children with CF have become apparent. Firstly, many school age children with CF now have $\mathrm{FEV}_{1}$ within the normal range even though they probably have lung disease. ${ }^{7}$ Secondly, reliable forced expiratory manoeuvres are difficult to obtain in children under the age of 5 years, with testing in the infant and preschool age groups being largely confined to specialist laboratories. ${ }^{8}$ As interest in monitoring younger patients increases, so does the need for alternative more sensitive measures of lung function that can be obtained in children of all ages.

Recent reports suggest that indices derived from multiple breath inert gas washout (MBW) may be more sensitive than spirometry in detecting lung disease in children with $\mathrm{CF} .{ }^{10}$ These measurements are performed during tidal breathing and early data from our laboratory and others suggest that they can be successfully obtained in infants and preschool children, as well as in older subjects. ${ }^{11-13}$ There is therefore increasing interest in the possible value of $\mathrm{MBW}$ in monitoring CF lung disease.

The aims of this study were (1) to investigate the relationship between parameters derived from MBW and from forced expiration in a population of healthy school age British children and children with CF; (2) to assess the within-test repeatability of MBW during uncontrolled breathing in healthy children and in those with CF; and (3) to compare MBW results from healthy school age British children with those recently reported for healthy Swedish children.

\section{METHODS}

Study subjects

School age children were defined as those aged between 6 and 16 years. Subjects with CF were recruited from the CF clinic at Great Ormond Street Hospital for Children. Subjects were excluded if they had a history of congenital cardiac disease requiring medical or surgical treatment; if they were born preterm (defined as birth before 37 weeks gestational age); or if they had neuromuscular or thoracic cage disorders likely to result in weakness of respiratory muscles or restriction of the thorax. Subjects were recruited opportunistically during an outpatient clinic or an inpatient stay between January and September 2001.

Control subjects were mostly recruited from the community, the remainder being healthy siblings from families of CF subjects. Exclusion criteria for control subjects were: any previous hospital admission for a respiratory condition; physician diagnosis of asthma or reactive airways disease at any time in the past; any history of chronic productive cough, recurrent wheezing, or shortness of breath within the previous 12 months; low birth weight (defined as weight less than $2.3 \mathrm{~kg}(5 \mathrm{lb})$ ); history of congenital cardiac disease, prematurity, or neuromuscular or bone disease as defined for the children with CF.

The study was approved by the research ethics committee of Great Ormond Street Hospital and the Institute of Child

\footnotetext{
Abbreviations: $\mathrm{FEV}_{1}$, forced expiratory volume in 1 second; FRC, functional residual capacity; FVC, forced vital capacity; LCI, lung clearance index; $\mathrm{MEF}_{25}$, maximal expiratory flow when $25 \%$ of $\mathrm{FVC}$ remains to be expired; $M B W$, multiple breath inert gas washout; $\mathrm{SF}_{6}$, sulfur hexafluoride
} 
Health. Informed written consent was obtained from the parents and written assent from the participants themselves when applicable.

\section{Lung function testing}

All lung function tests were performed at the Institute of Child Health. Children with CF were not tested during a pulmonary exacerbation, defined as described previously. ${ }^{14}$

\section{Spirometry: acceptability and analysis}

Forced expiratory manoeuvres were measured using a Jaeger Masterscope spirometer (Erich Jaeger AG, Wurzburg, Germany). A minimum of five maximal forced expiratory manoeuvres were performed. The best forced vital capacity (FVC) and $\mathrm{FEV}_{1}$ results were noted. The recording with the highest sum of $\mathrm{FEV}_{1}$ and FVC was used to obtain the maximal expiratory flow when $25 \%$ of $\mathrm{FVC}$ remains to be expired $\left(\mathrm{MEF}_{25}\right)$. Participants were encouraged to exhale for at least 3 seconds and were required to produce two repeatable $\mathrm{FEV}_{1}$ results (lower being within 5\% of the higher). ${ }^{15}$

\section{Multiple breath washout (MBW): apparatus and test procedure}

The participants were investigated in the sitting position during tidal breathing. During the MBW tests the subjects watched a video while the investigator watched the tidal volume trace on a computer screen. If the subject's tidal volume fell below $8 \mathrm{ml} / \mathrm{kg}$ or rose above $15 \mathrm{ml} / \mathrm{kg}$ body weight, he/she was asked to increase or decrease the tidal volume respectively. Other than this, subjects were encouraged to breathe normally and comfortably.

Details of the MBW apparatus and technique have been described previously. ${ }^{10}$ Briefly, all participants wore a nose clip and breathed through a Fleisch No.l pneumotachometer (PNT) via a mouthpiece. The PNT was connected to a differential pressure transducer (Validyne, Model MP 45-14871, Validyne Corp, CA, USA) and the flow signal was demodulated and amplified (Validyne MC1-10, Validyne Corp). The mouthpiece was connected to the PNT via a short connector into which the sampling tube from a respiratory mass spectrometer (AMIS 2000, Innovision A/S, Odense, Denmark) was placed. The external dead space of the system was measured as $15 \mathrm{ml}$.

Each test consisted of two phases. During the wash-in phase the subject inspired a dry gas mixture containing $4 \%$ sulfur hexafluoride $\left(\mathrm{SF}_{6}\right), 4 \%$ helium, $21 \%$ oxygen, and balance nitrogen. The gas was provided using a bias flow applied on the external opening of the PNT using a T-piece and a set of large bore tubes leading the gas to and from the T-piece. The bias flow was set at a level greater than the maximum inspiratory flow produced by the subject so that rebreathing did not occur. Wash-in was continued until the inspiratory and expiratory $\mathrm{SF}_{6}$ concentrations were stable and equal plus a further 15 seconds. At this moment the bias flow was stopped during expiration by disconnecting the Tpiece and washout was started. The washout phase continued until the end tidal $\mathrm{SF}_{6}$ concentration was below $0.1 \%$ (that is, $1 / 40$ th of the starting concentration). Recordings were only excluded if there was evidence of leakage. This could be identified by sudden falls in the tracer gas concentration or by failure of the tracer gas concentration to equilibrate during the wash-in phase.

\section{Calculation of lung clearance index}

The functional residual capacity (FRC) was first determined from the cumulative exhaled marker gas $\left(\mathrm{SF}_{6}\right)$ divided by the difference in end tidal $\mathrm{SF}_{6}$ concentration at the start of the washout and end tidal $\mathrm{SF}_{6}$ concentration at completion of the washout. The number of lung volume turnovers at each breath during the washout was calculated as the cumulative expired volume at that breath divided by the FRC. The cumulative expired volume was corrected for the external dead space in each breath.

The lung clearance index (LCI) was calculated as the number of turnovers needed to lower the end tidal tracer gas concentration to $1 / 40$ th of the starting concentration. ${ }^{16}{ }^{17}$

\section{Clinical information}

For children with CF, information on CF genotype and chronic bacterial respiratory infection was obtained from the child's physician. This information was not disclosed to the investigators until all lung function data had been analysed. Chronic bacterial infection was defined as three positive cultures of the same organism within a 6 month period.

\section{Data evaluation and statistical analysis}

FRC and LCI were calculated for each washout. For each parameter the mean, standard deviation (SD), and coefficient of variation $(\mathrm{CV}$, calculated as $100 \times \mathrm{SD} /$ mean) was calculated from the three recordings for each subject.

Height, weight, $\mathrm{FEV}_{1}$ and $\mathrm{MEF}_{25}$ results were converted into standard deviation scores (z-scores) using published reference data ${ }^{18}{ }^{19}$ with a z-score of less than -1.96 being categorised as abnormal. LCI was plotted against age, FEV $\mathrm{Z}$-score, and $\mathrm{MEF}_{25} \mathrm{Z}$-score. LCI, FEV 1 Z-score, and $\mathrm{MEF}_{25}$ $\mathrm{z}$-score for the CF and control groups were compared. Limits of normality, defined as mean $\pm 1.96 \mathrm{SD}$, were calculated for LCI from the control data and subjects with an LCI above the upper limit of normality were categorised as having an abnormal result.

The results from this study were compared with data previously collected in Swedish schoolchildren. ${ }^{10}$ These data were collected at the Department of Pediatrics, Central Hospital, Skövde, Sweden using an identical MBW apparatus and analysis system to that employed at the Institute of Child Health. Data from the Swedish laboratory were obtained directly from the lead investigator of the Swedish research group, Dr P Gustafsson. The Swedish group tested healthy children and children with CF aged 3-18 years using a face mask apparatus for children aged 6 years and younger. For the current analysis, only data from children aged 16 or younger who had performed MBW using a mouthpiece apparatus were included.

Group results are presented as mean (SD). Group comparisons are by unpaired $t$ test or $\chi^{2}$ test as appropriate. $95 \%$ CI for difference of means is presented for $t$ test results. A p value below 0.05 is regarded as statistically significant.

A sample size of 22 subjects in each group was calculated to be sufficient to detect a difference of 1 SD in LCI, FEV 1 $\mathrm{z}$-score, and $\mathrm{MEF}_{25} \mathrm{Z}$-score between $\mathrm{CF}$ and control groups, or between children measured at the Institute of Child Health and those measured in Skövde, with $90 \%$ power at the 5\% significance level.

\section{RESULTS}

A total of 57 children were studied, all of who completed three successful washouts. The spirometric results from two children with $\mathrm{CF}$ failed to meet the quality control criteria and were therefore excluded from further analysis.

Information regarding the remaining 55 children is summarised in table 1 . There were 22 subjects with CF aged 6.4-16.5 years and 33 control subjects aged 5.9-16.8 years. CF and control subjects were well matched for age and sex. The children with CF were significantly shorter and lighter than the control subjects.

Of the 22 children with CF, 15 were homozygous for the $\Delta$ F508 mutation while the other seven had one $\Delta$ F508 
Table 1 Characteristics of study subjects

\begin{tabular}{|c|c|c|c|}
\hline & $\begin{array}{l}C F \\
(n=22)\end{array}$ & $\begin{array}{l}\text { Controls } \\
(n=33)\end{array}$ & $\begin{array}{l}\text { Mean difference } \\
\text { ( } 95 \% \mathrm{Cl} \text { of difference) }\end{array}$ \\
\hline $\begin{array}{l}\text { Sex (\% male) } \\
\text { Age (years) } \\
\text { Weight }(\mathrm{kg}) \\
\text { Weight } \mathrm{z} \text {-score } \\
\text { Height }(\mathrm{cm}) \\
\text { Height } \mathrm{z} \text {-score }\end{array}$ & $\begin{array}{l}50 \% \\
11.5(3.2) \\
36.9(11.8) \\
-0.41(0.96) \\
142.5(18.6) \\
-0.61(1.20)\end{array}$ & $\begin{array}{l}42 \% \\
11.3(3.1) \\
41.1(14.7) \\
0.37(0.78) \\
147.4(18.3) \\
0.50(0.74)\end{array}$ & $\begin{array}{l}8 \%(-18 \text { to } 42) \\
0.2(-1.6 \text { to } 2.0) \\
-4.2(-11.8 \text { to } 3.3) \\
-0.78(-1.2 \text { to }-0.3)^{*} \\
-4.9(-15.1 \text { to } 5.2) \\
-1.11(-1.6 \text { to }-0.6)^{*}\end{array}$ \\
\hline
\end{tabular}

mutation and one other mutation. Ten children were chronically infected with Pseudomonas aeruginosa and, of the remaining 12 children, seven were chronically infected with Staphylococcus aureus. The children infected with Pseudomonas were significantly older than the other children (mean (SD) age Pseudomonas positive group 13.3 (2.9) years, Pseudomonas negative group 9.9 (2.8) years, mean difference 3.3 years (95\% CI 0.8 to 5.9 ), $\mathrm{p}=0.01$ ).

The mean (SD) coefficient of variation for LCI $\left(\mathrm{CV}_{\mathrm{LCI}}\right)$ was $6.2(2.9) \%$ for children with CF (range 2.5-15.4\%). For control children the mean (SD) $\mathrm{CV}_{\mathrm{LCI}}$ was $5.2(2.8) \%$ (range $0.3-11.8 \%$ ). There was no relationship between age and $\mathrm{CV}_{\mathrm{LCI}}$ for healthy children or for children with CF.

Table 2 presents results for LCI, $\mathrm{FEV}_{1} \mathrm{Z}$-score, and $\mathrm{MEF}_{25}$ $\mathrm{z}$-score analysed by diagnosis. For all parameters the difference between the two subject groups was highly significant. For LCI the upper limit of normality was calculated as 7.41 and the lower limit of normality as 5.49. Children with CF infected with Pseudomonas tended to have a lower $\mathrm{FEV}_{1}$ z-score than non-infected children with CF (mean difference -0.70 (95\% CI -2.00 to 0.59$), p=0.3)$ and a higher LCI (mean difference 2.34 (95\% CI -0.04 to 4.71 ), $\mathrm{p}=0.05$ ).

Figure 1 shows the relationship between LCI and age for the control subjects and those with CF. LCI was independent of age in healthy children but increased with age in children with CF $\left(r^{2}=0.30, \mathrm{p}=0.008\right)$.

The relationship between LCI and $\mathrm{FEV}_{1}$ for both subject groups is shown in fig $2 \mathrm{~A}$. In healthy children there was no relationship between LCI and FEV 1 but in children with CF LCI and $\mathrm{FEV}_{1}$ were negatively correlated $\left(r^{2}=0.63\right.$, $\mathrm{p}<0.0005)$. This figure also shows that, whereas 11 of the 22 children $(50 \%)$ with CF had an $\mathrm{FEV}_{1}$ within the normal range, with some of these children having an $\mathrm{FEV}_{1}$ z-score greater than zero, only one of $22(5 \%)$ had a normal LCI.

Figure 2B shows the relationship between LCI and $\mathrm{MEF}_{25}$ for both subject groups. In healthy children there was no relationship between LCI and $\mathrm{MEF}_{25}$ but, in children with $\mathrm{CF}$, LCI and $\mathrm{MEF}_{25}$ were negatively correlated $\left(r^{2}=0.46\right.$, $\mathrm{p}=0.001)$. This figure also shows that 12 of the 22 children with CF had an $\mathrm{MEF}_{25}$ result in the normal range, although none had an $\mathrm{MEF}_{25} \mathrm{Z}$-score greater than zero. The sensitivity and specificity of LCI for distinguishing children with CF from healthy controls were $95 \%$ and $97 \%$, respectively. The equivalent results for $\mathrm{FEV}_{1}$ and $\mathrm{MEF}_{25}$ were $50 \%$ and $100 \%$, and $45 \%$ and $100 \%$, respectively.
Table 3 and fig 3 present comparisons of results obtained in the current study with those previously obtained in Skövde, Sweden. LCI, $\mathrm{FEV}_{1}$, and $\mathrm{MEF}_{25}$ data from 24 healthy children aged 7.6-15.7 years were available from the Swedish laboratory. Age, height and weight were very similar for the two groups. The mean and range of values for LCI, $\mathrm{FEV}_{1}$, and $\mathrm{MEF}_{25}$ obtained from healthy children in the two centres were virtually identical. The upper limit of normality calculated from the Swedish data alone was 7.23. When the two populations were combined, the mean (SD) LCI was 6.40 (0.48), upper limit of normality 7.34 .

\section{DISCUSSION}

In this cross sectional study we compared spirometric measurements and ventilation distribution, measured by LCI, in a cohort of school age children with CF and in a matched cohort of school age control children. All healthy controls had normal $\mathrm{FEV}_{1}$ and $\mathrm{MEF}_{25}$ results. Normal values for LCI calculated from our control population were independent of age over the range studied, and were virtually identical to those recently reported from another laboratory. Approximately half of the children with CF had normal spirometric results, but nearly all of these children had abnormal ventilation distribution. Although this study was not powered to identify subgroup differences, a trend for higher LCI was noted in older children, in those with lower $\mathrm{FEV}_{1}$ and $\mathrm{MEF}_{25}$, and in those who were chronically infected with $P$ aeruginosa. In all children the coefficient of variation for LCI was low, indicating that this measure has good within-test repeatability.

In this study subjects were allowed to breathe spontaneously while watching a video, and the recordings were only excluded if there was evidence of leaking. Subjects were asked to keep their tidal volume between 8 and $15 \mathrm{ml} / \mathrm{kg}$ but MBW recordings were not excluded if they failed to do this. Despite these uncontrolled conditions, within-test repeatability was good with mean $\mathrm{CV}_{\mathrm{LCI}}$ below $7 \%$ for both CF and control groups, and no relationship was seen between subject age and repeatability.

Use of a mass spectrometer to perform MBW allows recording of several gas concentrations simultaneously (such as helium and carbon dioxide). Further analyses of recordings including these gases can be performed in the future when suitable software and algorithms are available,

Table 2 Lung function results presented by diagnosis

\begin{tabular}{llll}
\hline & CF & Controls & $\begin{array}{l}\text { Mean difference } \\
(95 \% \text { Cl of difference) }\end{array}$ \\
\hline $\mathrm{LCl}_{\mathrm{FEV}}$ z-score & $11.53(2.86)$ & $6.45(0.49)$ & $5.08(4.07 \text { to } 6.10)^{* * *}$ \\
$\mathrm{MEF}_{25}$ z-score & $-2.01(1.45)$ & $0.28(0.86)$ & $-2.29(-2.92 \text { to }-1.67)^{* * *}$ \\
\hline $\begin{array}{l}\text { Results are presented as mean (SD) unless specified. Difference calculated as CF - control. } \\
* * * \\
\text { p }<0.001 .\end{array}$
\end{tabular}




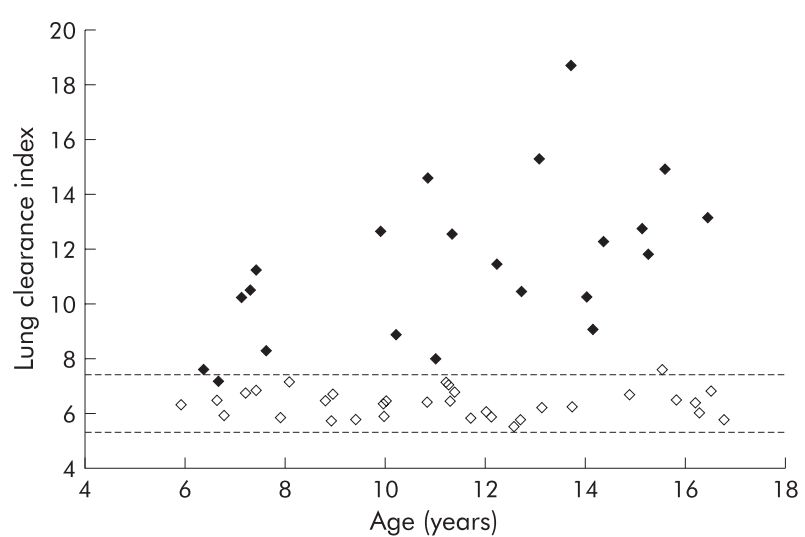

Figure 1 Age in years plotted against lung clearance index for control children (open circles) and children with CF (closed circles). Broken lines represent limits of normality for $\mathrm{LCl}$. Note that normal values for $\mathrm{LCl}$ are independent of age over the range studied.

offering the potential for more detailed information about lung function. In particular, a comparison of the phase III slopes obtained from gases of differing diffusivity, such as $\mathrm{SF}_{6}$ and helium, may give information about the site of peripheral airway pathology. ${ }^{20}$ However, we have noted that the phase III slope is affected by age, body size, and tidal volume. Further methodological work is necessary before our data can be interpreted in this way.

There have been previous studies of ventilation distribution in CF using similar methods. ${ }^{10}{ }^{21-25}$ The most recent studied Swedish children using the same methods and equipment as now used in our laboratory. ${ }^{10}$ The current study was powered to detect a difference in LCI of 1 SD between healthy children measured in London and those measured in Sweden. As can be seen from table 3, no significant difference was observed, with the mean difference in LCI between the two groups being 0.1 . The upper limit of normality calculated from the two populations was similar ( 7.49 for the UK population and 7.23 for the Swedish population). These differences between the healthy populations are small compared with the differences between healthy and CF populations (mean difference in LCI of 5.1 for the current study). The similarity of the results in healthy children from the two centres indicates that the MBW technique can be transferred between laboratories, and offers the possibility of collating data for future analyses.

The Swedish study also reported the LCI from 43 of the 70 children attending the CF clinic in Göteborg, most of whom had $\mathrm{FEV}_{1}$ and $\mathrm{MEF}_{25}$ results within the normal range. The majority of these children were found to have abnormal LCI although, in contrast to the findings in the current study, there was only a weak correlation between ventilation indices and spirometric indices. In the current study only a small subgroup (22/199) of children attending the CF clinic at Great Ormond Street Hospital for Children were recruited. As we did not attempt to recruit all children attending the clinic, nor did we try to take a representative sample, it is likely that some selection bias operated in recruitment to this study since children with more severe disease attend the clinic more frequently and were therefore more likely to be approached. The mean $\mathrm{FEV}_{1} \mathrm{z}$-score of our CF study population was -2.01 , and only half of our children had $\mathrm{FEV}_{1}$ within the normal range. This may explain why our CF population had a mean LCI of 11.53 compared with 8.33 in the Swedish CF population. A meaningful comparison of CF populations from two centres would require recruitment of representative samples and detailed information on treatment history and disease severity. These criteria were not met
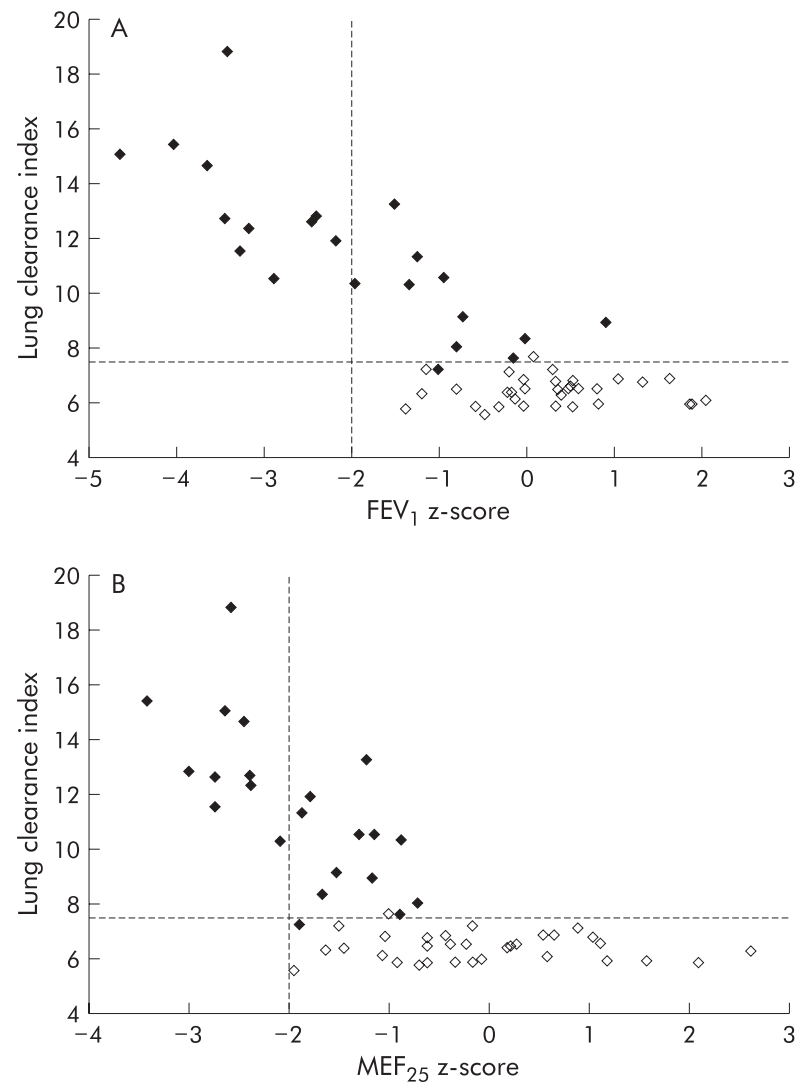

Figure 2 (A) Lung clearance index plotted against $\mathrm{FEV}_{1} z$-score for control children (open circles) and children with CF (closed circles). The vertical broken line represents the lower limit of normality for FEV $z$-score and the horizontal broken line represents the upper limit of normality for $\mathrm{LCl}$. Note that $50 \%$ of the children with CF had an $\mathrm{FEV}_{1}$ $z$-score within the normal range and $\mathrm{LCl}$ above the normal range. (B) Lung clearance index plotted against $\mathrm{MEF}_{25} \mathrm{z}$-score for control children (open circles) and children with CF (closed circles). The vertical broken line represents the lower limit of normality for $\mathrm{MEF}_{25}$ and the horizontal broken line represents the upper limit of normality for $\mathrm{LCl}$. Note that many children with CF have an $\mathrm{MEF}_{25}$ z-score within the normal range and $\mathrm{LCl}$ above the normal range.

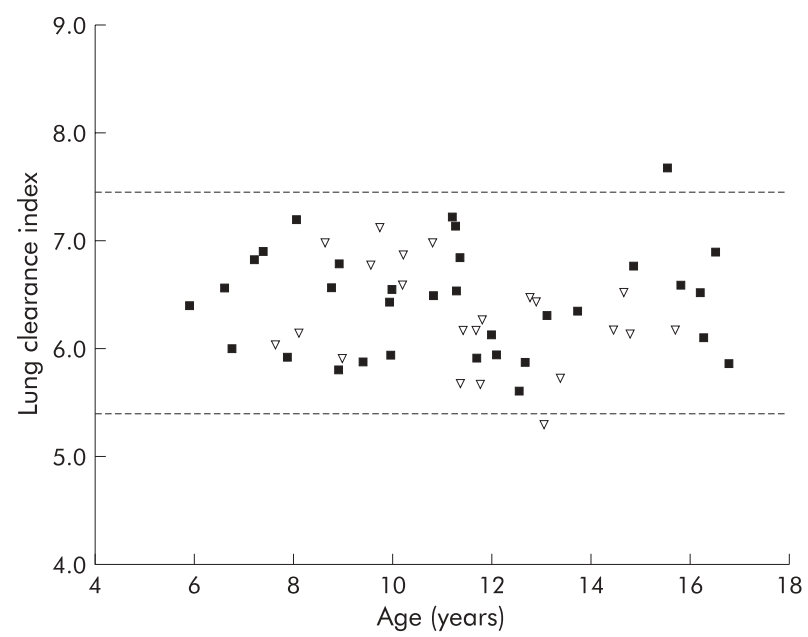

Figure 3 Lung clearance index (LCl) plotted against age for healthy children measured at the Institute of Child Health (closed circles) and in Sweden (open triangles). Broken lines represent limits of normality for $\mathrm{LCl}$, calculated from Institute of Child Health data. 
Table 3 Comparison of results obtained from healthy children at the Institute of Child Health, London with those previously reported from the Department of Pediatrics, Skövde, Sweden

\begin{tabular}{llll}
\hline & $\begin{array}{l}\text { UK } \\
(\mathbf{n}=\mathbf{3 3 )}\end{array}$ & $\begin{array}{l}\text { Sweden } \\
(\mathbf{n = 2 4 )}\end{array}$ & $\begin{array}{l}\text { Mean difference } \\
\text { (95\% Cl of difference) }\end{array}$ \\
\hline Age (years) & $11.3(3.2)$ & $11.4(2.2)$ & $-0.1(-1.6$ to 1.4$)$ \\
Weight (kg) & $41.1(14.7)$ & $40.3(11.7)$ & $0.8(-6.5$ to 8.1$)$ \\
Height $(\mathrm{cm})$ & $147.4(18.3)$ & $148.6(13.0)$ & $-1.2(-10.0$ to 7.6$)$ \\
LCl & $6.45(0.49)$ & $6.33(0.46)$ & $0.11(-0.14$ to 0.37$)$ \\
$\mathrm{FEV}_{1}$ z-score & $0.28(0.86)$ & $0.35(0.88)$ & $-0.07(-0.54$ to 0.39$)$ \\
$\mathrm{MEF}_{25} \mathbf{z}$-score & $-0.06(1.06)$ & $0.04(1.07)$ & $-0.1(-0.68$ to 0.48$)$ \\
\hline
\end{tabular}

The Swedish data have been published previously. ${ }^{10}$ Results presented as mean (SD) unless otherwise indicated. Difference calculated as UK - Sweden.

for the current analysis, but the consistency of LCI results in the healthy populations would allow future prospective studies using LCI as an outcome measure.

There was no correlation between LCI and $\mathrm{FEV}_{1}$ or $\mathrm{MEF}_{25}$ in healthy children, and this finding is not unexpected. Spirometric parameters are determined by many factors including the resistance and mechanical properties of the airways, total lung capacity, the elastic recoil pressure of the lungs, and muscular strength, some of which may be influenced by nutritional status. Conversely, an increase in LCI is caused by differences in specific ventilation between parallel lung units which may be due to changes in airway resistance or lung compliance. In contrast to spirometry, the LCI also reflects whether such pathology is irregularly distributed.

Cystic fibrosis is initially a disease of the airways which eventually progresses to parenchymal destruction. The extent of this destructive process varies between regions of the lung, rather than being uniformly distributed. It can therefore be expected that there will be some correlation between spirometric parameters and LCI in children with CF, but that this correlation will not be perfect. What we have shown is that all children with $\mathrm{CF}$ who have abnormal $\mathrm{FEV}_{1}$ or $\mathrm{MEF}_{25}$ have a markedly abnormal LCI (fig 2), and that most children with CF who have normal spirometric results have some derangement of LCI. These results are consistent with those reported by the Swedish group. ${ }^{10}$

This study cannot confirm whether this inhomogeneity is a manifestation of early CF lung disease, or whether it is an epiphenomenon present in most children with CF but unconnected to future prognosis. This question can only be answered by longitudinal studies tracking changes in LCI and forced expiratory parameters, and intervention studies examining the effect of treatment on ventilation distribution.

In this context, it is of note that MBW can be performed in both infants and preschool children. ${ }^{12} 2425$ Early data from our own laboratory suggest that the within-test repeatability of this measurement is equally good in these younger age groups, and that normal values for LCI are very similar to those reported here for older children. ${ }^{11}{ }^{13}$ This observation adds to the potential value of the MBW method, as interpretation of forced expiratory parameters can be confounded by the effects of growth and development. If the remarkable consistency of LCI in school age populations also applies to younger age groups, then this measure has considerable potential for tracking the effect of disease in growing populations.

This study shows that the MBW method can be accurately transferred between laboratories, that MBW parameters have good within-test repeatability in school age children, and that, in children with $\mathrm{CF}, \mathrm{MBW}$ parameters correlate with spirometric results but are often abnormal in children with normal spirometry. These results suggest that MBW may be a useful marker of early CF lung disease.

\section{ACKNOWLEDGEMENTS}

The authors thank the children and their families for taking part in this study, and also Ms Gail Slade of the Respiratory Function Laboratory, Great Ormond Street Hospital for Children who assisted with some of the measurements. Ms Slade sadly passed away before this manuscript was written.

\section{Authors' affiliations}

P Aurora, A Lindblad, C Oliver, J Stocks, Portex Anaesthesia, Intensive Therapy and Respiratory Medicine Unit, Institute of Child Health, London, UK

P Aurora, C E Wallis, Cardiorespiratory and Critical Care Division, Great Ormond Street Hospital for Children, London, UK

A Lindblad, P Gustafsson, Queen Silvia Children's Hospital,

Sahlgrenska University Hospital, Göteborg, Sweden

A Bush, Department of Paediatric Respiratory Medicine, Royal Brompton Hospital, London, UK

Funding: Dunhill Medical Trust, British Lung Foundation, Swedish Heart Lung Foundation. Research at the Institute of Child Health and Great Ormond Street Hospital for Children benefits from R\&D funding provided by the NHS Executive.

\section{REFERENCES}

1 Aurora P, Whitehead B, Wade A, et al. Lung transplantation and life extension in children with cystic fibrosis. Lancet 1999;354:1591-3.

2 Kerem E, Reisman J, Corey M, et al. Prediction of mortality in patients with cystic fibrosis. N Engl J Med 1992;326:1187-91.

3 Suri R, Metcalfe C, Lees B, et al. Comparison of hypertonic saline and alternate-day or daily recombinant human deoxyribonuclease in children with cystic fibrosis: a randomised trial. Lancet 2001;358:1316-21.

4 Frederiksen B, Lanng S, Koch C, et al. Improved survival in the Danish centertreated cystic fibrosis patients: results of aggressive treatment. Pediatr Pulmonol 1996;21:153-8.

5 Nir M, Lanng S, Johansen HK, et al. Long-term survival and nutritional data in patients with cystic fibrosis treated in a Danish centre. Thorax 1996;51:1023-7.

6 Stern RC. Denmark to the rescue. Pediatr Pulmonol 1996;21:151-2.

7 Tiddens HA. Detecting early structural lung damage in cystic fibrosis. Pediatr Pulmonol 2002;34:228-31.

8 Eigen $H$, Bieler $H$, Grant $D$, et al. Spirometric pulmonary function in healthy preschool children. Am J Respir Crit Care Med 2001;163:619-23.

9 Stocks J, Sly P, Morris MG, et al. Standards for infant respiratory function testing: what(ever) next? Eur Respir J 2000;16:581-4.

10 Gustafsson PM, Aurora P, Lindblad A. Evaluation of ventilation maldistribution as an early indicator of lung disease in children with cystic fibrosis. Eur Respir J 2003;22:972-9.

11 Aurora P, Oliver C, Gustafsson PM, et al. Multiple breath washout in healthy pre-school children and those with cystic fibrosis (CF). Eur Respir J 2002;20:209s.

12 Hjalmarson $\mathrm{O}$, Sandberg K. Abnormal lung function in healthy preterm infants. Am J Respir Crit Care Med 2002;165:83-7.

13 Liungberg H, Gustafsson P, Hulskamp G, et al. Increased ventilation inhomogeneity in infants with CF. Eur Respir J 2002;20:209s

14 Fuchs HJ, Borowitz DS, Christiansen DH, et al. Effect of aerosolized recombinant human DNase on exacerbations of respiratory symptoms and on pulmonary function in patients with cystic fibrosis. The Pulmozyme Study Group. N Engl J Med 1994;331:637-42.

15 Quanjer PH, Tammeling GJ, Cotes JE, et al. Lung volumes and forced ventilatory flows. Report Working Party Standardization of Lung Function Tests, European Community for Steel and Coal. Official Statement of the European Respiratory Society. Eur Respir J Suppl 1993;16:5-40. 
16 Edelman $\mathrm{NH}$, Mittman $\mathrm{C}$, Norris $\mathrm{AH}$, et al. Effects of respiratory pattern on age differences in ventilation uniformity. J Appl Physiol 1968;24:49-53.

17 Larsson A, Jonmarker C, Werner O. Ventilation inhomogeneity during controlled ventilation. Which index should be used? J Appl Physiol 1988:65:2030-9.

18 Rosenthal M, Bain SH, Cramer D, et al. Lung function in white children aged 4 to 19 years: I - Spirometry. Thorax 1993;48:794-802.

19 Freeman JV, Cole TJ, Chinn S, et al. Cross sectional stature and weight reference curves for the UK, 1990. Arch Dis Child 1995;73:17-24.

20 Van Muylem A, Baran D. Overall and peripheral inhomogeneity of ventilation in patients with stable cystic fibrosis. Pediatr Pulmonol 2000;30:3-9.
21 Habib RH, Lutchen KR. Moment analysis of a multibreath nitrogen washout based on an alveolar gas dilution number. Am Rev Respir Dis 1991;144:513-9.

22 Kraemer R, Meister B. Fast real-time moment-ratio analysis of multibreath nitrogen washout in children. J Appl Physiol 1985;59:1137-44.

23 Lutchen KR, Habib RH, Dorkin HL, et al. Respiratory impedance and multibreath $\mathrm{N}_{2}$ washout in healthy, asthmatic, and cystic fibrosis subjects. $J$ Appl Physiol 1990;68:2139-49.

24 Wall MA. Moment analysis of multibreath nitrogen washout in young children. J Appl Physiol 1985;59:274-9.

25 Couriel JM, Schier M, Hutchinson AA, et al. Distribution of ventilation in young children with cystic fibrosis. Pediatr Pulmonol 1985;1:314-8.

\section{LUNG ALERT}

The real impact of influenza?

A Thompson WW, Shay DK, Weintraub E, et al. Influenza-associated hospitalizations in the United States. JAMA 2004;292:1333-40.

A Armstrong BG, Mangtani P, Fletcher A, et al. Effect of influenza vaccination on excess deaths occurring during periods of high circulation of influenza: cohort study in elderly people. BMJ 2004;329:660.

$\Delta$ Wilkinson P, Pattenden S, Armstrong B, et al. Vulnerability to winter mortality in elderly people in Britain: population based study. BMJ 2004;329:647.

E ach year mortality increases in winter, especially in the elderly. Much of the excess is believed to be related to respiratory viral infections but robust data are scarce. Three recent papers cover this topic and provide further insights into the role of influenza.

Thompson et al provide data on national estimates of influenza associated hospital admissions in the US. This is important because previously only data on influenza associated mortality were available, which may incompletely reflect the severity of influenza infections. The authors used data from National Hospital Discharge Survey and WHO collaborating laboratories influenza surveillance to estimate the annual numbers of hospital admissions associated with influenza from $1979-80$ to $2000-01$. $8.6 \%$ of all primary admissions and $8.0 \%$ of any listed pneumonia and influenza hospital admissions were associated with influenza viruses. The total numbers of primary and influenza related hospital admissions increased in a linear fashion during the period investigated. Influenza associated hospital admissions rates and length of stay increased dramatically with age. Rates of hospital admission were lower during seasons in which $\mathrm{A}(\mathrm{HlNl})$ viruses predominated compared with $\mathrm{A}(\mathrm{H} 3 \mathrm{~N} 2)$. The authors conclude that the observed increase in influenza associated hospital admissions was due to aging of the population, the predominance of $\mathrm{A}(\mathrm{H} 3 \mathrm{~N} 2)$ viruses in many recent seasons, and the prolonged circulation of viruses in recent years. This study is, however, limited by the absence of previous health information such that it was not possible to determine which individuals were at risk for influenza complications and, since no information was available on vaccination status, assessment of vaccine effectiveness was not possible.

Vaccine effectiveness was investigated by Armstrong et al. They performed a prospective cohort follow up in 24535 subjects aged over 75 years, supplemented by weekly counts of influenza isolations, to estimate the protection against death provided by influenza vaccination. Overall mortality was lower in vaccinated people than in unvaccinated people. Vaccination significantly reduced deaths due to all cause and respiratory diseases. During the influenza season the proportion of deaths attributable to influenza was $13.4 \%$ in unvaccinated and $2.2 \%$ in vaccinated people, resulting in a derived estimate of vaccine effectiveness of $83 \%$. Vulnerability to confounding was substantially reduced in this study by a new approach avoiding direct comparison of mortality in vaccinated and unvaccinated groups, but comparing vulnerability within each group to increasing mortality associated with high circulation of influenza. However, the robustness and improved outcome specificity obtained by this method was at the cost of low precision, highlighted by the findings that only protection from all cause and respiratory mortality were statistically significant at conventional levels.

The overall determinants of vulnerability to winter mortality were examined by Wilkinson et al using a population based cohort study investigating people aged over 75 years recruited from primary care. Assessments included medical, sociodemographic, and socioeconomic data. Mortality was related to information on circulating influenza. Overall mortality in the winter months (December to March) was higher (100.1 deaths per 1000 person years) than in the other months (76.4 deaths per 1000 person years). Only female sex and a prior history of respiratory illness were associated with excess winter deaths.

Taken together, these studies show that significant numbers of influenza associated hospital admissions occur among the elderly and that influenza vaccination has a protective effect on mortality in these patients. The increase in winter mortality in elderly people seems particularly related to pre-existing respiratory illness and, surprisingly, female sex. 